\title{
Competências críticas ao desenvolvimento de mapas cognitivos de redes interorganizacionais*
}

\author{
José Osvaldo De Sordi** \\ Djair Picchiai*** \\ Manuel Antonio Meireles da Costa**** \\ Maria Aparecida Sanches*****
}

SumÁrio: 1. Introdução; 2. Metodologia; 3. Referenciais teóricos utilizados nas análises; 4. Análise das principais dificuldades encontradas pelos alunos no desenvolvimento do exercício proposto; 5 . Conclusões.

Summary: 1. Introduction; 2. Methodology; 3. Theoretical framework of the analises; 4. Analysis of the main problems found by the students in the proposed exercise;

5. Conclusions.

Palavras-chave: rede interorganizacional; diagrama de rede; mapa cognitivo.

KEY WORDs: inter-organizational network; network diagram; cognitive map.

\footnotetext{
* Artigo recebido em maio e aceito em ago. 2009.

** Doutor em administração pela Escola de Administração de Empresas de São Paulo da Fundação Getulio Vargas (Eaesp/FGV). Docente-pesquisador do Programa de Mestrado em Administração da Universidade Municipal de São Caetano do Sul (USCS). Endereço: Rua Iwakumi, 236 - CEP 13211-424, Jundiaí, SP, Brasil. E-mail: de.sordi@terra.com.br.

**** Doutor em administração pela Escola de Administração de Empresas de São Paulo da Fundação Getulio Vargas (Eaesp/FGV). Docente-pesquisador do Programa de Mestrado em Administração das Micro e Pequenas Empresas pela Faculdade Campo Limpo Paulista (Faccamp). Endereço: Rua Guatemala, 167 - CEP 13231-230, Campo Limpo Paulista, SP, Brasil. E-mail: djair.picchiai@ faccamp.br.

$* * * *$ Doutor em engenharia pela Universidade de São Paulo (USP). Docente-pesquisador do Programa de Mestrado em Administração das Micro e Pequenas Empresas da Faculdade Campo Limpo Paulista (Faccamp). Endereço: Rua Guatemala, 167 - CEP 13231-230, Campo Limpo Paulista, SP, Brasil. E-mail: profmeireles@uol.com.br.

****** Doutora em ciências da saúde pela Universidade Federal de São Paulo (Unifesp). Docentepesquisadora do Programa de Mestrado em Administração das Micro e Pequenas Empresas da Faculdade Campo Limpo Paulista (Faccamp). Endereço: Rua Guatemala, 167 - CEP 13231-230, Campo Limpo Paulista, SP, Brasil. E-mail:cidasanches@uol.com.br.
} 
Este artigo identifica alguns dos conhecimentos e habilidades requeridos para a compreensão e abstração de redes interorganizacionais por intermédio de diagramas de rede. Para tanto, realizou-se um exercício prático junto a 102 alunos da área de administração. No exercício, foi pedido o desenvolvimento de um diagrama de rede a partir da transcrição de falas de atores centrais de uma rede do cultivo de uva. Na fase de pré-análise das respostas, os pesquisadores identificaram aspectos críticos para abstração de redes interorganizacionais, reflexão que auxiliou a definir os códigos requeridos para exploração do material por meio de análise de conteúdo: abstração de organizações com mesma função na rede; abstração de macroprocessos que compõem a rede; abstração do ator central da rede. Além de apurar a grande dificuldade dos alunos para compreender e abstrair redes interorganizacionais, o exercício auxiliou na identificação de algumas competências críticas para tal, como: conhecimentos e habilidades referentes a entidades e seus relacionamentos, como os alcançados pela prática das técnicas de construção de modelo entidade-relacionamento; conhecimentos e habilidades de processos de negócio, em especial de atividades de decomposição e síntese de processos.

Critical capabilities for the development of cognitive maps of inter-organizational networks

This article identifies the knowledge and skills required for understanding and abstracting inter-organizational network through network diagrams. A practical exercise was applied to 102 business administration students asking them to draw a network diagram based on the transcripts of the statements of central actors in a viniculture network. The pre-analysis of the answers revealed critical aspects for inter-organizational network abstraction. This reflection helped define the required codes to explore the material through content analysis: abstraction of organizations with same function in the network; abstraction of the network's macro-processes; abstraction of the central actor of network. Besides identifying the students' great difficulty in abstracting and understanding inter-organizational networks, the research revealed of some of the required critical competencies: knowledge and skills related to entities and their relationships, such as those obtained by the use of construction techniques; knowledge and skills related to business processes, especially activities of decomposing and synthesizing processes.

\section{Introdução}

O conceito de rede interorganizacional implica a organização de pessoas e empresas em torno de interesses e objetivos comuns. Caracteriza-se pela postura dinâmica, com pouca hierarquia e muita conectividade entre seus atores. Só existe quando em movimento, sem a participação das partes, deixam de existir. As redes sociais têm um sentido mais amplo, pois tratam de 
indivíduos e organizações, seus valores, seus interesses e objetivos. A rede interorganizacional é um tipo de rede social, que assume um caráter sociotécnico e operacional.

Gestão da cadeia de fornecedores (supply chain management), gestão de cadeia colaborativa (collaborative network), arranjos produtivos locais (clusters) são exemplos de temas de interesse de pesquisa na ciência da administração, pertinentes a estudos interorganizacionais. Essas pesquisas concentramse em relações estabelecidas entre empresas que podem se configurar em uma rede. Tal conjunto de empresas pode ser representado e analisado por intermédio de diagrama de rede, que representa organizações como atores, ou nós de rede. Os relacionamentos interligam os diversos atores.

Os temas de pesquisa pertinentes a redes são de interesse tanto da academia quanto das próprias organizações. Taylor (2005:8) afirma que o gerenciamento da cadeia de suprimentos passou da função de suporte para habilidade essencial das organizações, envolvendo a empresa como um todo.

As cadeias de suprimentos são a última mina inexplorada. Hoje, o gerenciamento da cadeia de suprimentos é muito mais importante do que a manufatura como habilidade essencial, tanto que é possível, como exemplificaram a Nike e a Cisco Systems, dominar o mercado de determinado produto sem ter muito mais do que uma fábrica em operação.

A expressão redes de negócios é extremamente abrangente e pode, por exemplo, ser abordada a partir de dois paradigmas: conteúdo social, que afirma que a rede social é um padrão de convivência, constituindo-se as redes de negócios em subsistemas da rede social; e conteúdo estratégico, a partir de um planejamento das empresas (Ebers e Jarillo, 1997; Oliver e Ebers, 1998; Castells, 2000). Assim, as empresas buscariam nas redes obter uma posição mais competitiva. Miles e Snow (1992) afirmam que o nascimento organizado das redes passou a ocorrer a partir de 1980, com um quadro de muitas mudanças e predomínio de incertezas. Entre os motivos dessa situação estão o rápido desenvolvimento tecnológico e as mudanças de valores e comportamentos dos consumidores. Surgiram os movimentos de parcerias entre compradores e vendedores e as redes de organizações, para estabelecer relacionamentos de longo prazo e para o surgimento de interdependência e de confiança, caracterizando uma abordagem mais voltada aos aspectos de relações sociais.

A essência básica de uma rede é o fenômeno da coopetição. Esta palavra, que simultaneamente expressa cooperação e competição entre empresas, temse tornado crescentemente popular nos anos recentes, como atestam os tra- 
balhos de Harbison e Pekar Jr. (1998); Coy (2006); Gnyawali e Park (2009). Coy (2006:96) chega a exprimir que "dormir com o inimigo" ou aprender a trabalhar com rivais é muito importante para o sucesso da empresa. Por outro lado, Quintana-García e Benavides-Velasco (2004) mostram que a coopetição ajuda a incrementar a diversidade tecnológica e a combinar de forma complementar recursos de empresas rivais com vistas a desenvolver novas tecnologias e produtos. Esses aspectos positivos em relação às redes interorganizacionais ressaltam a importância de se mapear e conhecer seus atores.

Os elementos fundamentais de uma rede interorganizacional são os atores e as relações que se estabelecem entre eles. De acordo com Granovetter e colaboradores (1998:219) "uma relação entre dois autores tem força e conteúdo. O conteúdo inclui informação, conselho ou amizade, interesses compartilhados ou pertencimentos e, tipicamente, algum nível de confiança". Os atores da rede ao mesmo tempo em que a limitam são pontos a partir dos quais a rede se difunde. Castells (2005) afirma que, como estruturas abertas, as redes são capazes de se expandir de forma ilimitada, integrando novos nós, desde que compartilhem o mesmo código de comunicação.

Nohria e Eccles (1992) afirmam que existem três razões para o aumento do interesse no tema "redes interorganizacionais": a emergência da "nova competição"; o surgimento das tecnologias de informação e comunicação (TICs) que possibilitam uma maior capacidade de inter-relações entre firmas dispersas; e a consolidação da análise de redes como uma disciplina acadêmica, não somente restrita a alguns grupos de sociólogos.

Um aspecto fundamental é a capacidade da pessoa em compreender e abstrair as entidades constituintes da rede e as relações entre elas. Daí derivou-se a pergunta deste artigo: quais as principais dificuldades encontradas por estudantes de administração em termos de compreensão e explicitação de rede interorganizacional por intermédio de diagramas de rede?

O objetivo deste artigo é desenvolver uma reflexão acerca de aspectos críticos para a compreensão e representação de redes interorganizacionais, a fim de identificar conhecimentos e habilidades requeridas aos alunos de administração.

A representação de redes interorganizacionais organiza-se em torno de algumas variáveis estruturais do campo organizacional, tais como: a centralidade da rede, que pressupõe que os atores do centro da rede são estruturalmente dominantes. A centralidade está associada ao grau de envolvimento do ator em todas as relações no sistema (Galaskiewicz, 1979; Knoke e Burt, 1983) e é fundamental que seja compreendida e determinada. Outra variável importante é a posição dos atores na rede (associada à hierarquia da rede), 
variável que para Knoke (1994) e Marsden e Friedkin (1994) expressam subgrupos de coesão. Assim, e de acordo com Porter (2005) e Nilsson e Rapp (2004), o conhecimento da cadeia produtiva é importante para que uma empresa possa, efetivamente, criar valor para os clientes através da redução de custos e melhoria de desempenho dos produtos.

Para alcançar tal objetivo, foi desenvolvido um exercício que foi aplicado junto a 102 alunos da área de administração. No exercício, foi pedido o desenvolvimento de um diagrama de rede a partir da transcrição de falas de atores centrais de uma rede fictícia do cultivo de uva.

\section{Metodologia}

\section{Roteiro e procedimentos da pesquisa}

A pesquisa centrou-se na percepção de um problema, orientado para a prática do mundo real, referente a um tema pertinente aos interesses de acadêmicos e praticantes. Os pesquisadores solicitaram a alunos de administração que respondessem a um teste - desenvolvimento de um diagrama de rede - , ou seja, estabeleceu-se um diálogo entre professor e aluno, cuja resposta esperada é um diagrama, composto por ícones e textos.

O roteiro foi estruturado a partir da sugestão de Bardin (2009) de atividades necessárias para aplicação da técnica de análise de conteúdo, descrito na figura 1. Os procedimentos realizados estão descritos a seguir.

v Discussão em grupo entre quatro docentes-pesquisadores da área de gestão de redes para definição dos aspectos da diagramação de redes interorganizacionais, normalmente negligenciados ou de difícil compreensão pelos alunos de administração.

- Criação de uma questão a ser aplicada aos alunos de administração que solicita o desenvolvimento de um diagrama de rede a partir de informações provenientes de atores centrais de uma rede fictícia de cultivo da uva, ou seja, dos agricultores de uva. Informação transmitida na forma de transcrições das falas desses agricultores, conforme descrito no quadro "Exercício proposto aos alunos". Ao desenvolver as falas transcritas da questão, procurou-se abranger os aspectos da diagramação de rede, de difícil compreensão pelos alunos da administração.

- Resolução do exercício proposto com geração de um gabarito para correção das respostas dos alunos, como demonstrado na figura 3. 
- Desenvolvimento de texto explicativo contendo os conceitos, fundamentos e exemplos do diagrama de rede, além de três exemplos de diagramas de redes colaborativas - um bastante amplo, abrangendo toda a cadeia da indústria têxtil, descrito na figura 2, e outros dois de clusters regionais, um do vinho da Califórnia e outro da moda em couro da Itália (Porter, 1998).

Figura 1

Roteiro da pesquisa

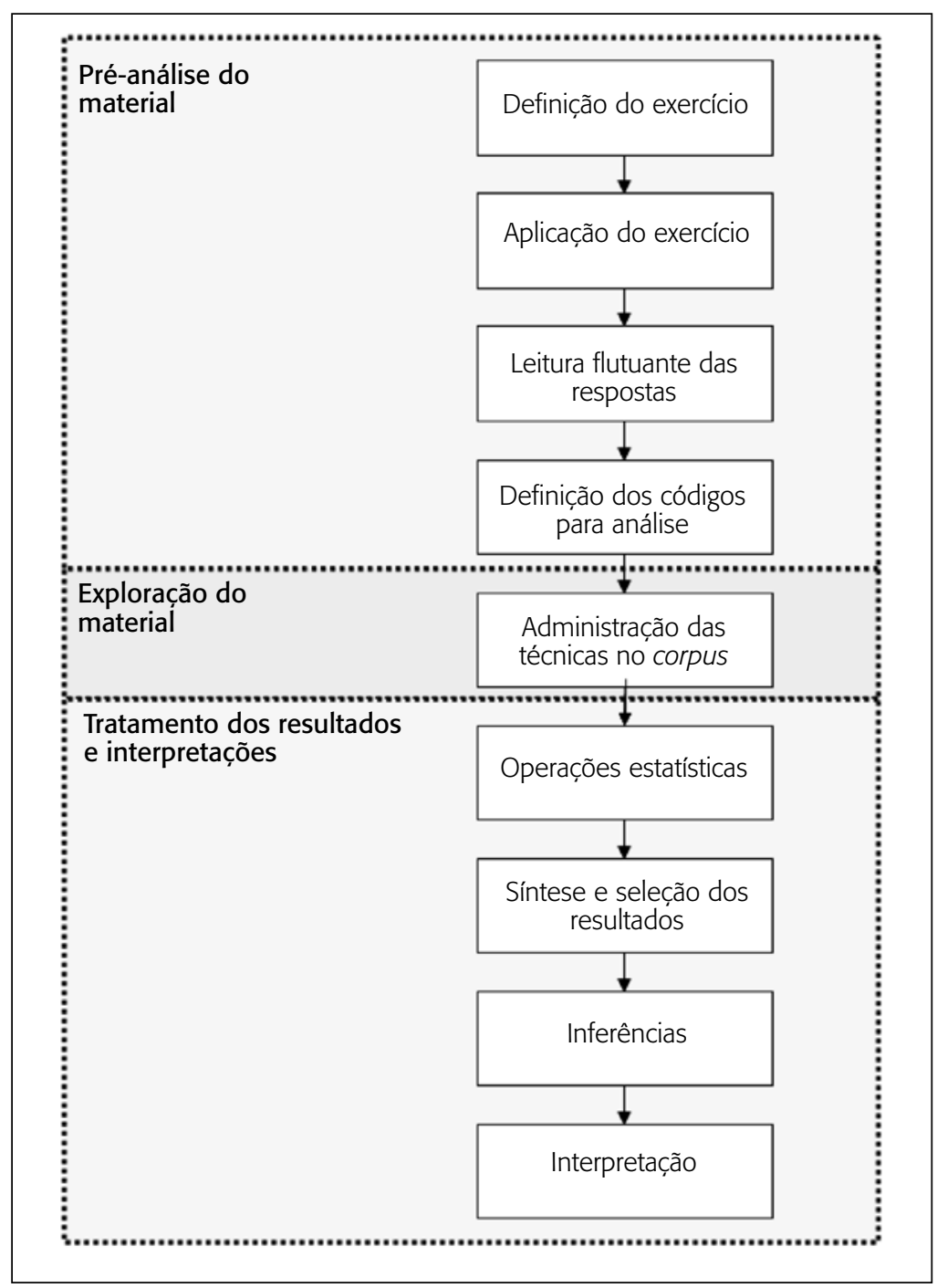

Fonte: Adaptado de Bardin (2009:128). 
- Conteúdo a ser apresentado aos alunos antes da questão.

\section{Exercício proposto aos alunos}

\section{1 - Elabore a representação gráfica da cadeia de valor para atividade agrícola do cultivo da uva, tendo como parâmetro as transcrições de entrevistas realizadas com agricultores locais.}

"Temos um ótimo relacionamento com as empresas Cabral, Telles, Mudinha e outras tantas, que produzem localmente mudas certificadas de videira que se adaptam muito bem às condições de nosso clima e solo."

"A instalação do Instituto de Pesquisa Agrícola do Estado em nossa cidade fortaleceu muito a competência do nosso Centro de Desenvolvimento de Videiras. Acredito que essa seja a justificativa da expansão de nossas empresas produtoras de mudas que atendem inclusive a outros estados."

"Temos uma cooperativa de trabalhadores rurais especializada nas atividades poda e cultivo de parreiras. Tanto prestamos serviços a não cooperados, mediante contrato de prestação de serviços, como atendemos aos cooperados, que têm direito a uma quantidade de horas de trabalho previstas ao longo do semestre."

"A cultura da lida com a uva foi assegurada com a implantação na década de 1980 da Escola Técnica Rural, ela colabora muito com a formação de pessoal para trabalhar nos vinhedos, considerando que nem todos os netos querem permanecer no campo e a mão de obra não é mais familiar como antes."

"A indústria de polpa de frutas trabalha muito próxima conosco, assegura a compra de boa parte de nossa produção. Para não haver dependência tão forte deles, asseguramos a venda de parte de nossa produção para varejistas da região e de outros estados."

"Para sermos mais competitivos em qualidade, decidimos privilegiar duas empresas transportadoras locais, tendo como contrapartida a compra de modernos veículos de transporte climatizados para nossas frutas. Conseguimos contratos com novos varejistas, principalmente alguns mais distantes fisicamente, em função dessa parceria."

"As vinícolas não são mais tão atrativas e fortes na região como antes, mas continuam a ser um ponto de escoamento importante para boa parte da nossa produção, pois muitos plantam uvas do tipo merlot."

"Somos o primeiro polo de produção de uva a oferecer uva de mesa com embalagens segundo a nova norma europeia, graças aos esforços dos nossos parceiros que desenvolveram embalagens $100 \%$ recicláveis."

Fonte: Desenvolvido pelos autores. 
- Identificação de quatro instituições de ensino superior com cursos lato sensu, MBA em gestão empresarial, que fosse viável a aplicação do questionário. Amostra de conveniência, pela seleção de instituições de conhecimento dos pesquisadores, todas da cidade de São Paulo (SP).

- Para cada uma das quatro instituições procedeu-se com a apresentação do texto explicativo sobre redes interorganizacionais, seguido da aplicação do questionário junto aos discentes.

\section{Figura 2}

Diagrama de rede do segmento têxtil

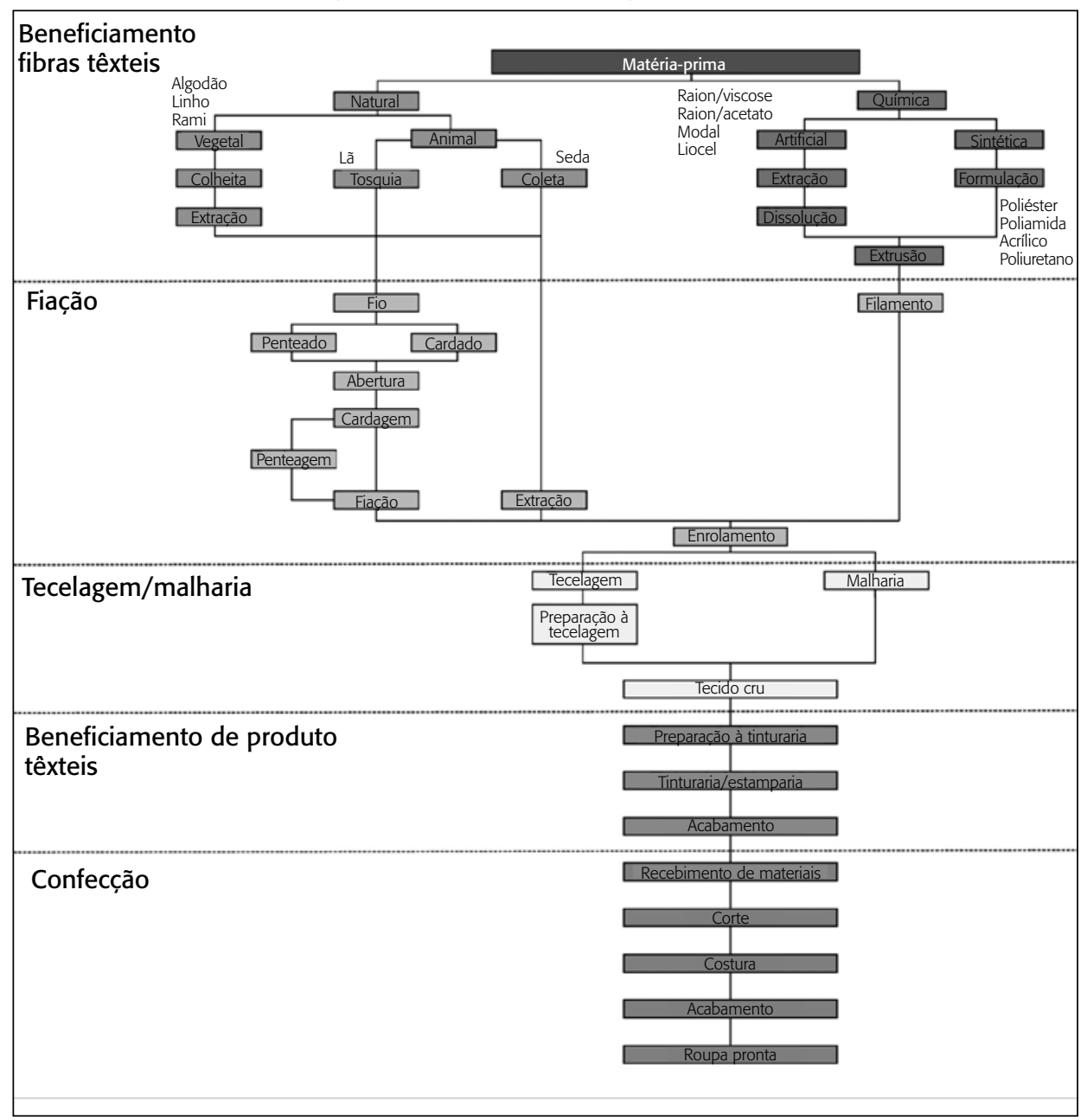

Fonte: lemi, citado por Gonçalves (2008:94). 
- Pré-análise por intermédio de uma leitura rápida das respostas ou como denomina Bardin (2009): "leitura flutuante das respostas".

- Definição dos códigos para desenvolvimento da análise de conteúdo. Segundo Bardin (2009), um dos papéis centrais do pesquisador está no trabalho de poda, aquele de delimitar as unidades de codificação ou registro. No exercício definiram-se os seguintes códigos para análise:

(C1) abstração de organizações com mesma função na rede em torno de representação única, ou seja, presença de uma entidade no diagrama de rede;

(C2) abstração de macroprocessos que compõem a rede, caracterizados por delimitação gráfica da(s) entidade(s) que o constituem além de um título;

(C3) abstração do ator central da rede com a entidade que representa o(s) ator(es) que realiza $(\mathrm{m})$ a atividade econômica central disposta no centro do diagrama da rede, com as demais entidades dispostas ao seu redor;

- Análise e avaliação das respostas dos discentes pela técnica de análise de conteúdo.

v Tabulação e preparo dos resultados apurados pela análise de conteúdo para aplicação de análise estatística.

v Análise estatística dos resultados apurados pela análise de conteúdo.

- Síntese e seleção dos resultados que permitem melhor compreensão das dificuldades dos alunos na elaboração de diagramas de rede.

v Inferências e interpretações sobre conhecimentos e habilidades necessárias para suprir tais dificuldades dos discentes.

\section{Análise dos dados}

A análise dos dados foi feita por meio de duas abordagens qualitativas: análise de conteúdo e estatísticas não paramétricas. A estatística não paramétrica não requer que a "população" seja normal. As amostras podem ser relativamente pequenas, não exigem nível intervalar; as medidas podem ser do tipo simples. Cabe observar que os testes paramétricos são mais precisos. Suas técnicas são válidas na hipótese de que a "população" é normal. Neste caso as amostras são de tamanho relativamente grande. 
Figura 3

Exemplo de "diagrama de rede" como resposta esperada ao exercício proposto

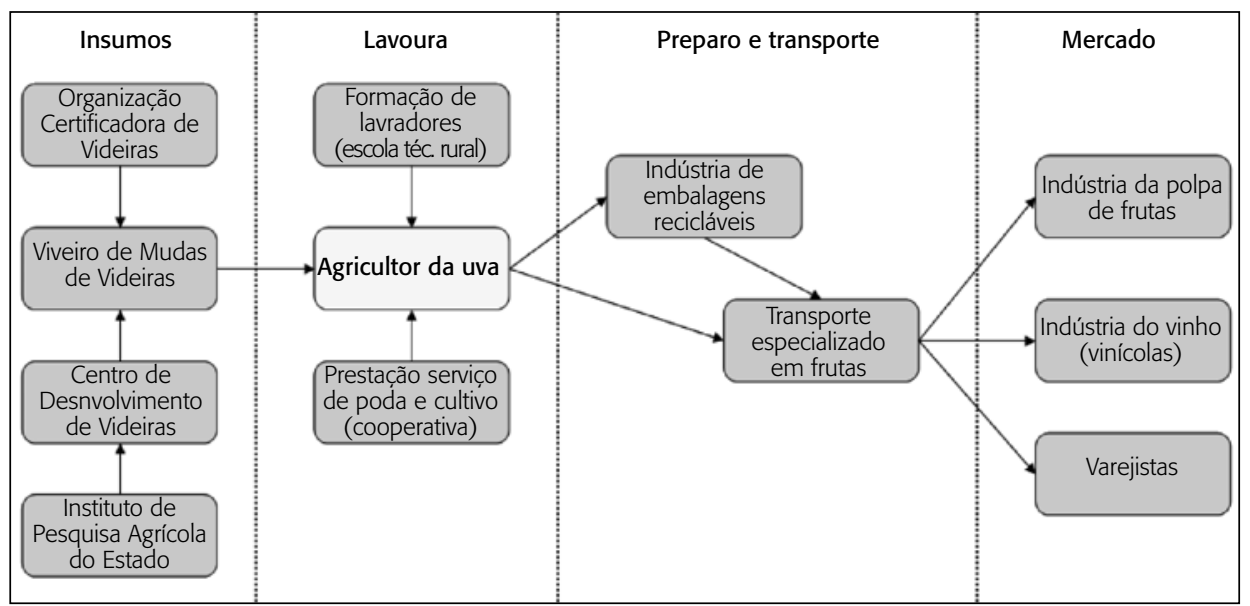

Os métodos não paramétricos podem ser aplicados a uma ampla diversidade de situações, porque não exigem populações distribuídas normalmente. Ao contrário dos métodos paramétricos, os não paramétricos podem, frequentemente, ser aplicados a dados não numéricos. Os métodos não paramétricos, em geral, envolvem cálculos mais simples do que seus correspondentes paramétricos, e, assim, são mais fáceis de entender. Os métodos não paramétricos tendem a perder informação, porque os dados numéricos são, com frequência, reduzidos a uma forma qualitativa. Os testes não paramétricos não são tão eficientes quanto os paramétricos. Com um teste não paramétrico, em geral necessitamos de uma amostra maior ou maiores diferenças para então rejeitarmos uma hipótese nula (Siegel e Castellan Jr., 1988:8).

As vantagens das técnicas não paramétricas apontadas por Baquero (1970:216) são: a normalidade da população e dos seus respectivos parâmetros é prescindida; são aplicadas às amostras obtidas de população diferente; as medidas podem ser do tipo simples de "escala nominal"; as amostras podem ser realmente pequenas; e os cálculos matemáticos são simples.

No que se refere às técnicas não paramétricas foi utilizado o teste $\chi^{2}$ (qui-quadrado). Foi feito um teste de aderência para medir o ajustamento ou concordância dos escores observados aos valores teóricos esperados ou deduzidos do ponto de vista matemático. 


\section{Referenciais teóricos utilizados nas análises}

A análise de dificuldades conceituais encontradas pelos alunos dos cursos de administração no desenvolvimento de diagramas de rede será pautada em três referenciais teóricos: Teoria Geral dos Sistemas (TGS), entidades e relacionamentos, e processo de negócio. A TGS é o principal constructo teórico, fundamental para o entendimento dos outros dois.

\section{Teoria Geral dos Sistemas (TGS)}

Historicamente, o esforço das organizações na procura das melhores práticas de negócios teve sua origem em 1911 quando Frederick Winslow Taylor publicou sua obra, Principles of scientific management, quase ao mesmo tempo em que Henry Ford revolucionava os processos de manufatura, inaugurando a sua linha de produção contínua. Taylor argumentava que a simplificação, os estudos de tempos e a experimentação sistemática eram as ferramentas indicadas para se encontrar o melhor caminho para executar uma tarefa, monitorá-la e avaliar os seus resultados (Harmon, 2003).

A TGS surgiu como uma crítica à abordagem científica e reducionista predominante no início do século XX, que reduzia as entidades. Por exemplo, um animal, para o estudo individual de suas propriedades e de suas partes ou elementos (órgãos ou células). A TGS direciona a análise do pesquisador para o todo, ou seja, para as relações entre as partes que se interconectam e interagem orgânica e sistemicamente.

A TGS aplicada à ciência da administração resultou em uma nova abordagem administrativa: a abordagem sistêmica para gestão das organizações. As abordagens administrativas anteriores não consideravam o lado externo da organização, trabalhavam com a especialização de assuntos internos da organização de formas estanques, simplificavam as organizações e, consequentemente, a gestão como um todo. Acabavam não auxiliando o gestor das organizações a entender e administrar toda a complexidade envolta nas organizações.

A partir da aplicação dos conceitos da TGS na gestão das organizações, passou-se a considerar a complexidade crescente das organizações. A visão limitada e simplificada da escola científica da administração já era questionada no Ocidente desde 1918. A pesquisadora Mary Parker Follet insistia em que os administradores deveriam considerar a empresa um todo (modelo holístico), não apenas seus indivíduos e grupos, mas, inclusive, os fatores ambientais como política, economia e biologia (Graham, 1997). 
Ludwig Von Bertalanffy é reconhecidamente o primeiro autor a defender a visão organicista na biologia e o papel da simbologia na interpretação da experiência humana. É aceito como um dos fundadores da Teoria Geral dos Sistemas - e a conotação de geral significa que seus conceitos e suas principais aplicações são observadas na ciência em geral e em toda a escala de disciplinas, da física à biologia, da sociologia à filosofia, da economia à administração. Para ele "se um objeto é um sistema deve ter certas características gerais dos sistemas, qualquer que seja o sistema" (Bertalanffy, 1975:121).

Já na década de 1920, o autor advogava uma concepção organísmica na biologia, que acentuasse a consideração do organismo em totalidade ou sistema e visse o principal objetivo das ciências biológicas na descoberta dos princípios de organização em seus vários níveis. Apontou a "analogia organísmica" da biologia com as instituições, chamando em sua defesa outros autores.

Bertalanffy (1975) introduziu o tema teoria geral de sistemas para descrever as características principais de organizações como sistemas com as seguintes importantes propriedades: organizações (tal como organismos) são compostos por sistemas; todos os sistemas tendem a encontrar o equilíbrio; e todas as organizações são sistemas abertos pelo fato de afetarem e serem afetados pelo meio ambiente.

Bertalanffy (1975:61) caracterizou a Teoria Geral dos Sistemas como “(...) uma ciência geral da 'totalidade' (...) uma disciplina lógico-matemática, em si puramente formal, mas aplicável às várias ciências empíricas".

A possibilidade de descrições abstratas, não dependentes da natureza específica de um sistema, foi apontada como a razão para a escolha dos sistemas de equações diferenciais para o estudo dos sistemas em geral (Bertalanffy, 1975; Rapoport, 1976).

Maruyama (1963) concebe sistemas como redes de múltiplas interações circulares, tanto de ampliação de desvios quanto de neutralização de desvios. Entretanto, o autor chama a atenção para a existência de relações de influência entre dois ou mais elementos, em ambas as direções, que não implicam necessariamente causalidade mútua. Cita o exemplo de uma empresa A que produz matéria-prima, e outra, $B$, que produz equipamentos usando a matéria-prima de A (A compra equipamentos de B). Supondo que uma terceira empresa C demande tanto uma grande quantidade de matéria-prima de $A$ como de equipamentos de B, simultaneamente crescerão as vendas de A e de B. Entretanto, nesse caso, o aumento da atividade não é causado por relações de causalidade mútua, mas sim por um terceiro fator, a indústria C. Assim, se duas empresas mantêm relações entre si e se ambas as empresas mantêm relações com outras empresas, é necessário distinguir as relações de causalidade mútua entre A e 
B das demais interações que podem provocar resultados semelhantes. Outra importante contribuição de Maruyama (1963) foi o "diagrama de sinal de enlace causal", ou simplesmente "diagrama de enlace causal", concebido para descrever as interações de sistemas complexos.

Para Morin (1992), o conteúdo do termo "organização", na perspectiva sistêmica, é substancialmente distinto da perspectiva clássica. Nas ciências clássicas a "organização" é um conceito estático, de ordem e regras invariáveis, associado à noção de "estrutura" da visão mecanicista. Na perspectiva sistêmica é uma noção com características dinâmicas, que se refere a processos que se automantêm em sistemas naturais ou que são mantidos em sistemas construídos pelo homem. A organização como noção sistêmica central, segundo Morin (1992), engloba as seguintes características:

- a organização em sistemas físicos e em todos os biológicos ativos envolve "suprimento, estoque, distribuição e controle de energia, bem como, consumo e dissipação de energia em seu trabalho" (Morin, 1992:127);

v como consequência da característica anterior, a organização produz entropia - degradação do sistema e da própria organização - e negentropia - a regeneração do sistema, incluindo a reorganização permanente das relações que especificam a própria organização do mesmo;

v a organização envolve interações que especificam a abertura do sistema (trocas com o seu ambiente) ao mesmo tempo que mantém o "fechamento organizacional" (manutenção de um padrão de interações fechadas, responsáveis pela autonomia e integridade do sistema);

- organização significa a criação de ordem onde impera o determinismo sistêmico. Entretanto, essa ordem pode ser flexível, contemplando zonas de incerteza, disputa e liberdade. A desordem é um ingrediente inevitável, gerado complementarmente à própria atividade organizacional;

- em função da característica anterior, a presença simultânea da ordem e da desordem, a organização envolve incertezas e antagonismos;

v o "ser" e a "existência" são características relacionadas à organização sistêmica, quando essa assume a forma auto-organizadora. A "auto-organização gera ser e existência" (Morin, 1992:128).

Os teóricos organizacionais Katz e Kahn (1978) estiveram entre os pioneiros na aplicação dos conceitos sistêmicos a organizações sociais. A partir do conceito de sistema aberto destacaram o lugar central dos processos de impor- 
tação, transformação e exportação de energia (produtos) como fonte básica da autoperpetuação das organizações. Katz e Kahn (1978) procuraram, inicialmente, identificar o que é uma organização de um ponto de vista geral. A ideia básica dos autores é de que organizações possuem objetivos relacionados às funções que desempenham no ambiente. Criticam, entretanto, as posições tradicionais, por conceberem as funções das organizações sociais a partir dos propósitos dos seus líderes ou grupos predominantes.

Katz e Kahn (1978) estavam especialmente interessados em organizações de grande escala, que dependessem explicitamente das suas entradas e saídas para renovar os seus padrões cíclicos internos. A concepção geral de Katz e Kahn (1969:89) era:

Todos os sistemas sociais, incluindo organizações, consistem em atividades padronizadas de um número de indivíduos. Além disso, essas atividades padronizadas são complementares ou interdependentes com respeito a uma saída comum ou resultado; são repetitivas, relativamente duradouras e limitadas no espaço e no tempo. Se o padrão de atividades ocorre somente uma vez ou em intervalos não previsíveis, não podemos falar de uma organização. A estabilidade ou recorrência de atividades pode ser examinada em relação à entrada energética no sistema, à transformação das energias dentro do sistema, e ao produto resultante ou saída energética.

Do ponto de vista das concepções sistêmicas gerais, a formulação mais importante agregada por Katz e Kahn (1978) foi a identificação dos padrões de estruturas sociais com as cadeias energética de eventos - entrada de energia, sua transformação, até o fechamento do ciclo que realimenta o processo. As organizações eram concebidas, dessa forma, como um sistema complexo, constituindo uma rede de entidades relacionadas. Tais propriedades possibilitaram a utilização do modelo entidade-relacionamento para a sua representação.

\section{Entidades e relacionamentos}

O modelo conceitual de entidades e relacionamentos foi introduzido por Chen (1990). A larga utilização desse modelo se deve basicamente ao fato de ele conseguir expressar situações do mundo real com simplicidade, facilidade e riqueza semântica, por meio de símbolos com uma conceituação rigorosa.

De acordo com Chen (1990), a visão de uma dada realidade baseiase no relacionamento entre entidades, que retratam os fatos que governam 
essa mesma realidade, e que cada um (entidade ou relacionamento) pode possuir atributos (qualificadores da realidade). $\mathrm{O}$ conceito de abstração permite ao analista separar da realidade em estudo as partes que são realmente relevantes para o desenvolvimento do sistema de informações e excluir da modelagem todos os aspectos que não exercem influência sobre o ambiente a ser modelado.

Segundo Chen (1990), entidade é uma "coisa" que pode ser distintamente identificada por suas características descritas pelos atributos. A entidade Viveiro de Mudas de Videira, por exemplo, é caracterizada por uma série de atributos que qualquer organização dessa natureza deve possuir: nome da organização, endereço, tipo de uva desenvolvida, nome do agrônomo responsável, entre outros dados. No modelo entidade-relacionamento (E-R) cada organização com esse perfil é considerada uma instância. Assim, na questão há três organizações que desenvolvem mudas, ou seja, três instâncias da entidade Viveiro de Mudas de Videira. Independentemente da quantidade de organizações (instâncias da entidade) dessa natureza, dentro de uma rede, a estrutura de dados se aplica igualmente, tanto para três organizações quanto para 300 ou 3 mil. No diagrama E-R, desenvolvido por Chen (1990), uma entidade é representada por um retângulo, assim como no diagrama de rede interorganizacional.

O modelo E-R propõe que a realidade seja visualizada sob três pontos de vista: os objetos que compõem a realidade; os tipos de informação ou características que se deseja conhecer sobre os objetos que compõem a realidade; e a forma como estes objetos interagem entre si. Desta forma, o modelo E-R é composto por três conceitos, segundo Chen (1990):

v entidade - objeto ou evento do mundo real, distintamente identificado e tratado como uma categoria definida, acerca da qual armazenamos dados. A sua representação é um retângulo;

v atributo - característica inerente a uma entidade. Os atributos representam as informações, que caracterizam exclusivamente a entidade, e que desejamos registrar;

v relacionamento - associação, com um significado, entre duas ou mais entidades.

\section{Processos de negócio}

O termo processo de negócio, embora abstrato, pode ser exemplificado de diversas formas. Uma definição bastante simplista e prática para entendê-lo é 
por meio de analogia com processos tangíveis como os realizados nas linhas de produção em que se pode verificar um trabalho executado por meio de diferentes atividades sequenciais, que corroboram para a composição do produto final. Muitas das técnicas e conceitos aplicados à gestão por processos foram concebidas em áreas fora da administração, sobretudo na engenharia de produção, mais especificamente nas práticas do gerenciamento operacional (Armistead et al., 1995).

O processo de negócio, assim como o processo produtivo, é composto por diversas etapas de produção ou atividades a serem executadas. Dessa forma, a sequência de atividades para se vender um produto pode ser definida como processo de venda. A ideia de dividir o trabalho em atividades sequenciais surgiu em meados do século XVIII, no início da Revolução Industrial, quando a mecanização exigiu a divisão do trabalho. Exemplo clássico está no célebre Inquérito sobre a natureza e as causas da riqueza das nações, sólido livro em dois volumes com mais de mil páginas, publicado em 1776 por Adam Smith (1993), que relata a experiência da fabricação de alfinetes dividida em 11 operações.

O conceito de divisão do trabalho em tarefas é o ponto de consenso entre os principais pensadores da administração contemporânea quanto à definição de "processo de negócio", conforme se pode observar nas definições abaixo:

- "um conjunto de atividades cuja operação conjunta produz um resultado de valor para o cliente" (Hammer e Champy, 1997);

- "uma série de etapas criadas para produzir um produto ou serviço, incluindo várias funções e preenchendo as lacunas existentes entre as diversas áreas organizacionais, objetivando com isso estruturar uma cadeia de agregação de valor ao cliente" (Rummler e Brache, 1995);

、 "é o local onde os recursos e competências da empresa são ativados, a fim de criar uma competência organizacional capaz de preencher suas lacunas para gerar uma vantagem competitiva sustentável" (Beretta, 2002);

v "um grupo de tarefas interligadas logicamente, que utilizam os recursos da organização para geração de resultados predefinidos, visando apoiar os objetivos da empresa" (Harrington, 1991);

- "uma organização de atividades de trabalho, com início, fim e com entradas e saídas claramente definidas" (Davenport, 1994). 
Todos esses conceitos são oriundos da TGS e foram introduzidos na ciência da administração. Da grande diversidade de conceitos para processos de negócio, extraiu-se a essência comum à maioria das descrições: processos de negócio são fluxos de trabalhos que atendem a um ou mais objetivos da rede interorganizacional e que proporcionam agregação de valor sob a ótica do cliente final. No exemplo da figura 2 estão evidenciados os principais fluxos de trabalho da rede têxtil. As linhas pontilhadas do diagrama e o nome à esquerda desses segmentos descrevem as cinco macroetapas produtivas do segmento têxtil: beneficiamento de fibras têxteis, fiação, tecelagem/malharia, beneficiamento de produto têxtil e confecção.

\section{Análise das principais dificuldades encontradas pelos alunos no desenvolvimento do exercício proposto}

Da fase de pré-análise das respostas, definiram-se os códigos a ser empregados na análise de conteúdo, identificados como muito importantes para que o discente possa compreender e expressar-se por meio de diagramas de redes interorganizacionais. Tais códigos são os seguintes:

- (C1) organizações com mesma função na rede;

- (C2) macroprocessos que compõem a rede;

- (C3) ator central da rede.

A generalização de organizações que desempenham uma mesma atividade dentro da rede (C1) foi a dificuldade com maior frequência de ocorrência entre os alunos que realizaram o exercício. Conforme pode se observar no consolidado das respostas, descrito na tabela $2,68,18 \%$ dos alunos da amostra não apresentaram evidências do domínio dessa abstração. A evidência poderia ser consubstanciada em duas situações do exercício: a primeira relativa aos três viveiros de mudas citados na transcrição, "temos um ótimo relacionamento com as empresas Cabral, Telles, Mudinha e outras tantas"; e a segunda com relação às duas transportadoras citadas, "para sermos mais competitivos em qualidade, decidimos privilegiar duas empresas transportadoras locais". Nos diagramas desenvolvidos pelos alunos, muitos criaram três entidades independentes, correspondentes aos três viveiros citados no texto, bem como, representaram duas transportadoras distintas, conforme pode-se observar na figura 4 . 
Figura 4

Exemplos de dificuldades para generalização de organizações (entidades) que desempenham mesmo papel na rede interorganizacional

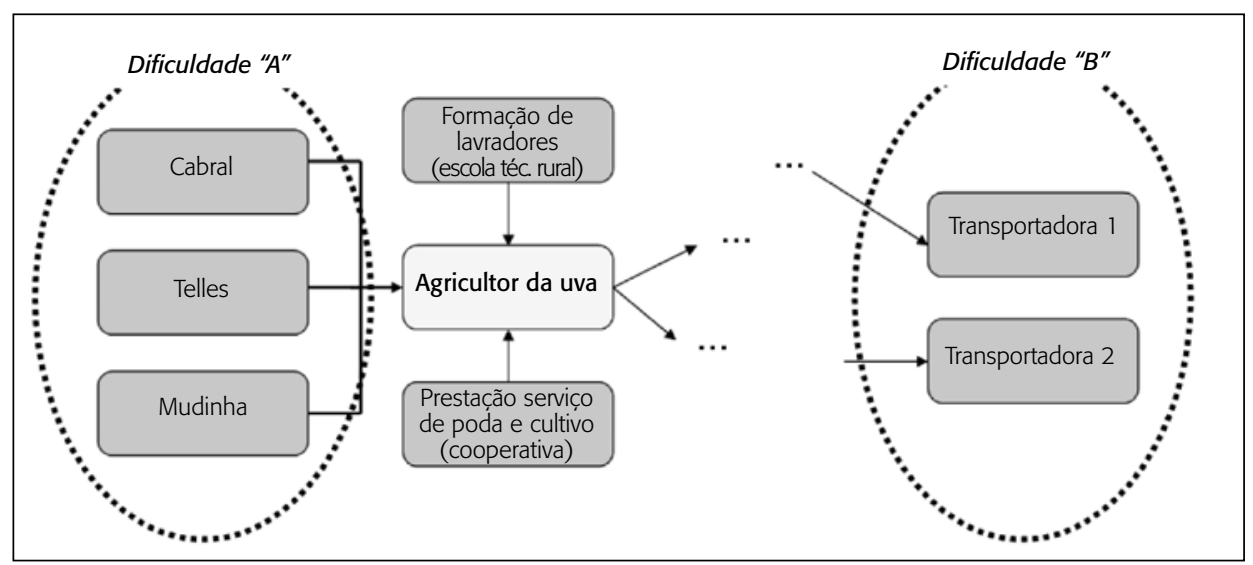

O domínio de conceitos de modelagem de dados, exercitados, por exemplo, por intermédio da técnica de modelo entidade relacionamento, capacitam analistas de negócios e administradores a identificar conjuntos de atores que desempenham um mesmo papel na rede. O conceito de entidade representa objetos distintos, porém de mesma natureza, caracterizado pelo mesmo conjunto de atributos ou características. A partir do domínio do conceito de entidade nota-se que tanto a empresa Cabral, quanto a Telles e a Mudinha são similares para o contexto da rede, ou seja, são objetos de mesma natureza: desenvolvem mudas de videiras. Por essa razão, o insight de abstrair, de caracterizar todos os viveiros como um player (ator) da rede - viveiros de mudas de videiras - conforme descrito na figura 3.

Outro aspecto a ser destacado com relação aos atores (ou entidades) da rede é com relação à denominação destes, caracterizada por um substantivo e não por verbo. Exemplo típico de nome impróprio ocorrido no exercício foi, por exemplo, de entidade com o título transportar frutas, enquanto o correto seria transporte especializado em frutas. Muitos alunos confundiram o desenvolvimento da representação gráfica de rede com fluxograma de atividades, que apresenta retângulos com verbos, ou seja, títulos de atividades, de tarefas executadas ao longo do fluxo de trabalho.

O segundo aspecto problemático, evidenciado pelas análises de conteúdo e estatísticas descritivas, foi a identificação de macroprocessos que 
compõem a rede (C2). Do total de discentes, 66,67\% não trabalharam ou evidenciaram esse conceito em suas respostas. No exemplo de resolução válida do exercício proposto pelos pesquisadores (figura 3), os macroprocessos definidos foram: insumos, lavouro, preparo e transporte, e mercado. O problema mais encontrado foi a não descrição ou indicação de macroprocessos, ou seja, diagramas contendo apenas entidades e enlaces entre elas.

Os conceitos e técnicas descritos no referencial teórico sobre processos de negócios são muito oportunos para exercitar fundamentos e habilidades de síntese de atividades, como solicitado no exercício. A habilidade de sintetizar independe do nível da abstração dos elementos envolvidos. Um tecnólogo em processamento de dados desenvolve fluxogramas compondo passos elementares (comandos de programas) em fluxos de trabalho, um analista de negócios caracteriza um processo de negócio compondo processos.

A dificuldade dos discentes em identificar o ator central da rede (C3) - o "agricultor da uva" - ocorreu com 53,03\% dos respondentes. Quanto a esse aspecto cabe uma reflexão em relação ao domínio dos discentes da TGS, a capacidade deles perceberem uma rede interorganizacional como um sistema.

O discente com discernimento da visão sistêmica (TGS) é capaz de identificar redes empresariais como sistema; a rede fictícia descrita no exercício proposto, também seria compreendida como um sistema. O domínio dos fundamentos da TGS implica a compreensão de sistemas serem compostos por entidades, com relações entre elas e com objetivo e meio ambiente comum. A reflexão do objetivo comum implica a identificação do objeto ou função central da rede. No exercício, isso conduziria à identificação da uva como objeto central da cadeia, bem como do ator central da rede: o agricultor, a entidade que cultiva a uva.

\section{Estatística descritiva dos resultados}

A figura 5 mostra os resultados obtidos pelos alunos em relação aos códigos analisados. Os resultados estão tabulados por turma. Um total de 102 alunos de cursos de pós-gradução lato sensu em gestão empresarial constituíram as cinco turmas divididas por quatro instituições de ensino. 
Figura 5

Respostas dos alunos

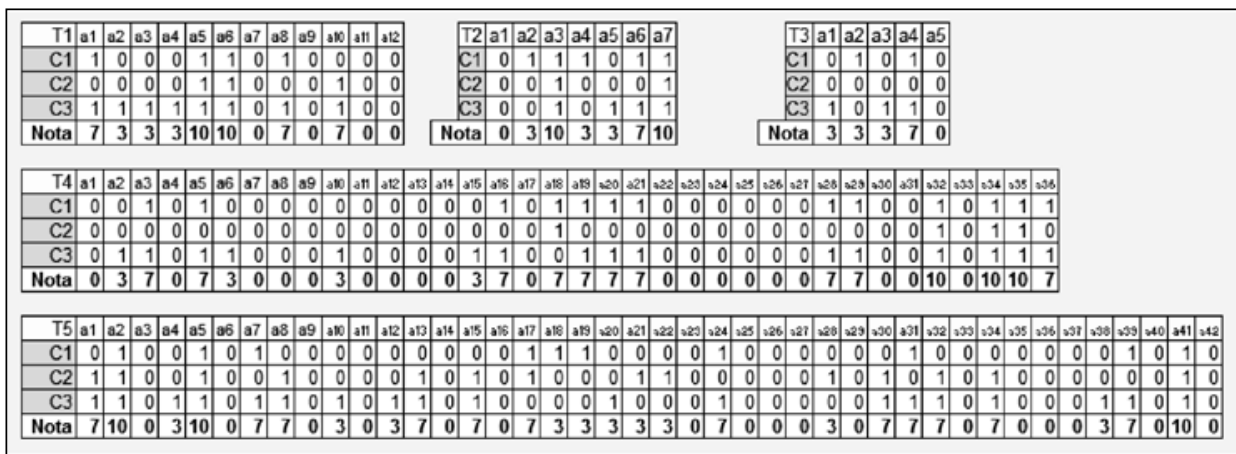

Legenda: $T$ = turmas (5); C = códigos analisados (3); 1 = conteúdo observado; 0 = conteúdo não observado.

As estatísticas descritivas são sinteticamente apresentadas na tabela 1. Os valores exibidos mostram um desempenho inferior da turma T4, cuja mediana diferiu significativamente das medianas das demais turmas. A turma T4 é uma turma composta, predominantemente, por alunos oriundos de cursos das áreas de biomédicas e, por tal característica, distingue-se das demais turmas compostas, predominantemente, por alunos egressos de cursos de bacharelado em administração.

Tabela 1

Estatísticas descritivas

\begin{tabular}{|lrrrrrl|}
\hline Discriminação & T1 & T2 & T3 & T4 & T5 & Total \\
\hline Tamanho da amostra & 12 & 7 & 5 & 36 & 42 & 102 \\
Mínimo & 0 & 0 & 0 & 0 & 0 & \\
Máximo & 10,0 & 10,0 & 7,0 & 10,0 & 10,0 & \\
Mediana & 3,0 & 3,0 & 3,0 & 0,0 & 3,3 & \\
Primeiro quartil (25\%) & 0,0 & 3,0 & 3,0 & 0,0 & 0,0 & \\
Terceiro quartil (75\%) & 7,0 & 8,5 & 3,0 & 6,7 & 6,7 & \\
\hline
\end{tabular}

Dado o resultado significativamente diferente apresentado pela turma T4, ela foi removida das análises subsequentes com o objetivo de se obter resultados mais consistentes, como mostra a tabela 2. Essa tabela exibe a frequência observada de concordâncias das turmas em relação aos códigos. Por exemplo, a turma T1, 33,33\% dos alunos observaram o código C1; 25\% deles 
observaram o código C2 e dois em cada três observaram o código C3. A tabela mostra que, de forma geral, o código C1 foi observado por 31,82\% dos alunos; o código C2 foi observado por 33,33\%; e o código C3 foi observado por cerca de $47 \%$ dos alunos.

Tabela 2

Análise da frequência da concordância em relação aos códigos

\begin{tabular}{|c|c|c|c|c|c|c|c|c|c|c|c|}
\hline \multicolumn{5}{|c|}{ \% de concordâncias } & \multicolumn{4}{|c|}{ Qtde. } & \multicolumn{3}{|c|}{$\%$ conc. para as quatro turmas } \\
\hline Turma & 1 & 2 & 3 & 5 & 1 & 2 & 3 & 5 & Acert. & Total & $\%$ \\
\hline $\mathrm{C} 1$ & 33,33 & 71,43 & 40,00 & 23,81 & 4 & 5 & 2 & 10 & 21 & 66 & 31,82 \\
\hline C2 & 25,00 & 28,57 & 0,00 & 33,33 & 3 & 2 & 3 & 14 & 22 & 66 & 33,33 \\
\hline C3 & 66,67 & 57,14 & 60,00 & 45,24 & 8 & 4 & 0 & 19 & 31 & 66 & 46,97 \\
\hline
\end{tabular}

A tabela 3 mostra, pelo teste $\chi^{2}$ (qui-quadrado) elaborado no software estatístico BioEstat 5.0, que não há diferença significativa ao nível de confiança de $95 \%$, quanto a predominância de algum código. Isso significa dizer que os alunos foram pesquisados de forma igual: não utilizam o conceito de entidade representando objetos distintos; não conseguem identificar os macroprocessos contidos na rede; e não reconhecem o ator central da rede.

Tabela 3

Teste $\chi^{2}$ (qui-quadrado): resultados

\begin{tabular}{|lc|}
\hline Soma das categorias & 112.120 \\
Qui-quadrado & 3.727 \\
Graus de liberdade & 2 \\
(p) & 0,1551 \\
\hline
\end{tabular}

Da articulação da superfície dos textos, ou seja, dos diagramas analisados e dos fatores que determinaram as características neles produzidas, em especial dos aspectos atrelados aos três códigos analisados, seja pela sua correta inserção, pela sua ausência ou pela sua má compreensão, evidenciou-se que os alunos de administração possuem muitas dificuldades para representar um diagrama de redes a partir de relatos de atores da mesma. Constatou-se nos resultados da amostra pesquisada a não compreensão clara dos conceitos de diagramação de redes e do próprio entendimento da complexidade da rede em movimento. 


\section{Conclusões}

Entre os resultados da pesquisa está a identificação de alguns aspectos de difícil compreensão pelos discentes da administração na atividade de desenvolvimento de diagramas de rede interorganizacionais: (C1) organizações com mesma função na rede; (C2) macroprocessos que compõem a rede; e (C3) ator central da rede. Constatou-se, também, a pouca percepção dos membros da amostra com relação a aspectos característicos de redes, a saber: a rede como organizações multifacetadas; a rede com estruturas horizontalizadas, não hierárquicas; e a rede e sua governabilidade.

Pela importância do conceito de redes interorganizacionais é necessário refletir sobre as competências - em seu sentido mais amplo de conhecimentos, habilidades e atitudes (Le Boterf, 1999) — requeridas aos que almejam estudar, compreender e explicitar redes interorganizacionais. Consequentemente, isso também expressa um ponto relevante aos docentes no planejamento de suas aulas e atividades associadas a redes interorganizacionais.

Para uma análise eficaz dos resultados obtidos, é importante destacar uma característica da técnica de análise de conteúdo empregada na presente pesquisa: "o interesse não está na descrição dos conteúdos, mas sim no que estes nos poderão ensinar após serem tratados" (Bardin, 2009:40). Segundo Henry e Mascovici (1968, citado por Bardin, 2009:42), o objetivo central da análise de conteúdo não é "o estudo da língua ou da linguagem, mas sim a determinação mais ou menos parcial das condições de produção dos textos". Tem-se como foco central da análise de conteúdo a articulação entre: "a superfície do texto, descrita e analisada (pelo menos alguns elementos característicos) e os fatores que determinaram estas características, deduzidos logicamente".

Seguindo o método sugerido por Bardin (2009), a partir das deficiências dos discentes evidenciadas pela condução das técnicas de análise de conteúdo e descrição estatística dos resultados advindos da codificação dos corpus (respostas), buscou-se compreender os "fatores que determinaram estas características, deduzidos logicamente". Das inferências e interpretações dos pesquisadores sobre os conhecimentos e habilidades necessárias para suprir as deficiências dos discentes para o desenvolvimento de diagramas de rede temse: o domínio dos fundamentos e conceitos da TGS como necessários à atividade de análise e explicitação de redes interorganizacionais. Técnicas analíticas como modelo entidade-relacionamento e decomposição de processos auxiliam não apenas no exercício dos fundamentos da TGS, mas abrangem elementos pertinentes ao contexto das redes interorganizacionais. 
Uma habilidade essencial para explicitação de redes interorganizacionais, por intermédio de diagramas, é a abstração de entidades da rede. Conforme exposto no referencial teórico, as técnicas de modelagem de dados, como por exemplo o modelo entidade-relacionamento que desenvolve, não apenas o conceito, mas a prática de identificação e definição de entidades e de relacionamentos entre estas.

O domínio de conceitos e técnicas atrelados a processos de negócios direciona o analista a uma visão mais ampla do conjunto de afazeres e responsabilidades para entrega de um produto ou serviço de qualidade. O que agrega valor ao cliente? Com quais recursos? São questões direcionadoras dos trabalhos de gestão por processos que condiciona o analista a ater-se a aspectos importantes da rede, como: produto ou serviço a ser entregue, insumos importantes, principais atividades, sua governabilidade e seus atores. Na rede interorganizacional estudada, os procedimentos típicos de decomposição e síntese da análise de processos também indicariam a "uva" como o principal produto da cadeia, assim como destacaria o "agricultor" como o ator central da rede.

O discernimento das entidades constituintes da rede - os seus atores - é pré-requisito para compreensão das redes interorganizacionais. Tal discernimento, conciliado com a percepção temporal e sequencial dos principais eventos de negócio que ocorrem entre atores da rede - os relacionamentos entre os atores - , capacita o analista de redes a identificar recortes, ou melhor, decompor o propósito da rede em processos de negócios. Em cursos de administração é muito comum os alunos praticarem os fundamentos da TGS em disciplinas como "organização \& métodos" ou "administração de sistemas de informação". Técnicas para desenvolvimento de diagramas de estado, diagramas entidade-relacionamento e diagramas de decomposição de processos são abordadas nessas disciplinas que desenvolvem, respectivamente, boa fundamentação para compreensão de eventos de negócios, entidades (ou atores) e segmentação ou delimitação de processos de negócios. Isso deve ser uma das razões para o desempenho superior, embora não adequado, das turmas compostas por alunos graduados em administração em comparação com a turma 4, composta por alunos oriundos de cursos das áreas de biomédicas.

Como continuidade da investigação deste artigo, recomenda-se a aplicação do mesmo teste, porém, atendo-se a delimitar e trabalhar previamente com duas amostras distintas: uma que tenha recebido conteúdo e experiência prática com exercícios de modelo E-R e de processos de negócio e outra que não tenha recebido tal informação. 


\section{Referências}

ARMISTEAD, C.; HARRISON, A.; ROWLANDS, P. Business process re-engineering: lessons from operations management. International Journal of Operations \& Production Management, Bradford, v. 15, n. 12, p. 46-58, 1995.

BAQUERO, G. Métodos de pesquisa pedagógica. São Paulo: Loyola, 1970.

BARDIN, L. Análise de conteúdo. 4. ed. Lisboa: Edições 70, 2009.

BERETTA, S. Unleashing the integration potential of ERP system. Business Process Management Journal, Bradford, v. 8, n. 3, p. 254-277, 2002.

BERTALANFFY, L. Teoria geral dos sistemas. Petrópolis: Vozes, 1975.

CASTELLS, M. Materials for an exploratory theory of the network society. British Journal of Sociology, v. 51, n. 1, p. 5-24, Jan./Mar. 2000.

. Sociedade em rede: a era da informação, economia, sociedade e cultura. São Paulo: Paz e Terra, 2005.

CHEN, P. Gerenciando banco de dados: a abordagem entidade-relacionamento para projeto lógico. São Paulo: McGraw Hill, 1990.

COY, P. Sleeping with the enemy. Business Week, New York, p. 96-97, Aug. 2006.

CRESWELL, J. Projeto de pesquisa: métodos qualitativo, quantitativo e misto. 2. ed. Porto Alegre: Bookman, 2007.

DAVENPORT, T. H. Reengenharia de processos: como inovar na empresa através da tecnologia de informação. 5. ed. Rio de Janeiro: Campus, 1994.

EBERS, M.; JARILLO, J. The construction, forms and consequences of industry networks. International Studies of Management and Organizations, v. 27, n. 4, p. 3-21, Winter 1997-98.

GALASKIEWICZ, J. The structure of community organizational networks. Social Forces, South Boundary, v. 57, n. 4, p. 1346-1364, June 1979.

GNYAWALI, D. R.; PARK, B.-J. Co-opetition and technological innovation in small and medium-sized enterprises: a multileved conceptual model. Journal of Small Business Management, Florida, v. 49, n. 3, p. 308-330, 2009.

GONÇALVES, C. O. A comunicação entre o design e o departamento produtivo de uma confecção de vestuário: um caso no segmento de surfwear. 2008. 95 f. Dissertação (Mestrado em Gestão de Negócios) — Universidade Católica de Santos, Santos, 2008. 
GRAHAM, Pauline (Org.). Mary Parker Follet: profeta do gerenciamento. Tradução de Eliana Hiocheti e Maria Luiza de Abreu Lima. Rio de Janeiro: Qualitymark, 1997.

GRANOVETTER, M.; SWEDBERG, R. The sociology of economic life. Cambridge: Westview, 2001.

HAMMER, M.; CHAMPY, J. Reengineering the corporation. London: Nicholas Brealey Publishing, 1997.

HARBISON, R. J.; PEKAR JR., P. Smart alliances. San Francisco: Jossey-Bass, 1998.

HARRINGTON, J. H. Business process improvement. Nova York: McGraw Hill, 1991.

HARMON, P. Business process change: a manager's guide to improving, redesigning, and automating processes. EUA: Morgan Kaufmann Publishers, 2003.

KATZ, D.; KAHN, R. L. Common characteristics of open systems. In: EMERY, F. E. (Ed.). Systems thinking. Pequim Books, 1969.

; _. Psicologia social das organizações. Atlas: São Paulo, 1978.

LE BOTERF, G. Competénce et navigation professionnelle. Paris: Éditions d'Organisation, 1999.

KNOKE, D. Political networks: the structural perspective. Cambridge: Cambridge University Press, 1994.

MARSDEN, P. V.; FRIEDKIN, N. E. Network studies of social influence. In: WASSERMAN, S.; GALASKIEWICZ, J. (Orgs.). Advances in social networks analysis: research in the social and behavioral sciences. London: Sage, 1994.

MARUYAMA, M. The second cybernetics: deviating-amplifying mutual causal process. New York: American Scientist, 1963.

MILES, R.; SNOW, C. Causes of failure in network organizations. California Management Review, p. 53-72, Summer 1992.

MORIM, E. The concept of system and the paradigm of complexity. In: MARUYAMA, M. Context and complexity: cultivating contextual understanding. New York: SpringerVerlag, 1992.

NILSSON, F.; RAPP, B. Understanding competitive advantage: the importance of strategic congruence and integration. New York: Springer-Verlag, 2004. 
NOHRIA, N.; ECCLES, R. G. Information and search in the creation of new business ventures: the case of the 128 Venture Group. Networks and organizations, p. 240-261. Boston: HBS Press, 1992.

OLIVER, A.; EBERS, M. Networking network studies: an analysis of conceptual configurations in the study of inter-organizational relationships. Organizational Studies, v. 19, n. 4, p. 549-583, 1998.

PORTER, M. E. Clusters and the new economics of competition. Harvard Business Review, p. 77-90, Nov./Dec. 1998. . Estratégia competitiva. 4. ed. Rio de Janeiro: Campus, 2005.

QUINTANA-GARCIA, C.; BENAVIDES-VELASCO, C. A. Cooperation, competition and innovative capability: a panel data of European dedicated biotechnology firms. Technovation, Amsterdan, v. 24, n. 3, p. 927-938, 2004.

RAPOPORT, A. Aspectos matemáticos da análise geral dos sistemas. In: Teoria dos sistemas. FGV, 1976. (Série Ciências Sociais).

RUMMLER, G.; BRACHE, A. Improving performance. São Francisco: Jossey-Bass, 1995.

SIEGEL, S.; CASTELLAN JR., N. J. Nonparametric Statistics for the behavioral sciences. 2. ed. New York: McGraw Hill, 1988.

SMITH, A. Riqueza das nações. Lisboa: Fundação Calouste Gulbenkian, 1993.

TAYLOR, D. A. Logística na cadeia de suprimentos: uma perspectiva gerencial. São Paulo: Pearson, 2005. 